\title{
Turnaround Reform Efforts in a Rural Context: How Community and Culture Impart Change
}

\author{
Ian Mette \\ University of Wyoming
}

This article furthers research on the necessary components of what supports successful school turnaround, and also explores how and why two rural schools taking part in a Midwest State Turnaround School Project were successful in implementing school turnaround policy. Perceptions of building principals, district administrators, and regional support staff implementing turnaround policy were considered. Data were collected from 13 participants and analyses focused on the culture created and leadership provided by two rural school districts during the State Turnaround Schools Project implementation. Previous research has detailed district communication, district support of the turnaround principal, and shared leadership as important factors. However this article explores how and why the two participating rural school districts were successful implementing school turnaround and identifies the cultural and community conditions that support school turnaround in a rural setting.

Keywords: turnaround schools, school turnaround, school reform, accountability policy, rural turnaround

This study explored how four school districts, two rural and two urban, implemented a State Turnaround Schools Project. It compared cultural settings and community involvement in two successful rural school districts and two unsuccessful urban school districts. Duke (2008) defines the term turnaround school as a reform effort to improve chronically low student achievement on standardized tests in a rapid manner, over a period of two or more consecutive years, using a highly prescriptive process that focuses on data-driven instruction to produce results and revamp the organizational instructional process.

In rural areas, schools face significant challenges, such as retaining effective principals and teachers, maintaining strong community partnerships, and meeting accountability standards without the help of increased funding (Erwin, Winn, \& Erwin, 2011; Monk, 2007). Previous research (Mette, 2013) has detailed the importance of turnaround schools clearly communicating with turnaround consultants and support personnel, providing district support and promoting community involvement, and the necessity of employing a shared leadership and shared accountability approach. However there is a real need to detail not just what comprises successful turnaround, but also to identify how and why these rural schools were successful in their turnaround policy implementation and initiative. Thus, this article seeks to bridge the gap between theory and practice, particularly regarding the impact and implementation of federally-funded programs in rural school districts that promote wide, sweeping reform efforts that are relatively uninformed by research.

\section{Turnaround School Policy}

When President Obama proposed signing the reauthorization of the Elementary and Secondary Education Act in March 2010, the United States Department of Education published a document titled A Blueprint for Reform, which presents a "reenvisioned federal role in education" for turning around America's lowest-performing schools (U.S. DOE, 2010, p. 2). Within this document, the federal government suggests rapid and dramatic changes to our nation's lowest performing schools, using purportedly innovative approaches to challenge traditional school instruction. However, turnaround policy provides a pejorative focus on using standardized tests as the main method of measuring school improvement performance and typically ignores socioeconomic factors, such as poverty and race (Trujillo \& Renée, 2012). As such, turnaround school policy is seen as a lightning rod for debate among researchers and practitioners as policy makers and consulting companies continue to increase their influence on reform efforts within the American public school system.

The School Improvement Grant (SIG) initiative, which provides funding for the nation's lowestperforming schools (U.S. Department of Education [DOE], 2011), allows districts to use a portion of the 
grant funding to partner with nonprofit organizations to assist in turnaround initiatives (U.S. DOE, 2010). These flexible funding mechanisms have created a large body of relatively recently written turnaround literature that contains methodological errors and provides an over reliance on standardized test scores to measure improved school performance (Trujillo \& Renée, 2012). Moreover, turnaround school policy has blurred the line between the private and public sectors, using the notion of turnaround policy as a commodity that can be sold and bought using a market-based approach to solve America's educational problems (Mette, 2013).

Turnaround school policy has historical roots in the business world, drawing on research from the organizational science of the 1980s (Murphy, 2008), attempting to link literatures that describe the turnaround of other failing organizations outside the education sector in the hopes of extrapolating guidelines to help schools undertake similar successful turnarounds. Moreover, academics posit there are lessons to be learned from the business world for educators and policy makers, specifically giving greater focus and attention towards leadership, efficiency, continuous monitoring of outcomes, and quality assessment (Murphy, 2010). The organizational sciences turnaround literature from the 1980s points to these areas of improvement as well. For example, O’Neill (1986) defined turnaround as a process that results in an organization ending its decline, requiring a prolonged implementation to respond to the needs of a changed environment. Additionally, in order for the turnaround strategy to be effective, a leader must analyze the specific needs of an organization and match appropriate strategies to reverse decline (Bibeault, 1982). In other words, a one-size-fits-all approach does not work for organizational turnaround; thus strategies must be developed based on the demands specific to the industry (Harrigan, 1988).

While there is a large body of literature on the concept of organizational turnaround in the private sector, few research-based sources exist regarding the application of turnaround efforts in schools (Boyne, 2006; Leithwood \& Strauss, 2008; Murphy \& Meyers, 2008). Additionally, a swath of organizational science research concludes that turnaround efforts result in failure much more often than success (Pearce \& Robbins, 1993; Shuchman \& White, 1995; Slatter, Lovett, \& Barlow, 2006). Therefore, researchers and practitioners should take a critical approach when analyzing the choice of the federal government to sponsor a reform initiative that has little evidence to support the likelihood of an initiative translating from the private sector to the public sector. Moreover, when schools are successful in implementing turnaround school policy, the evidence of how this was accomplished should be examined and studied for future implications for practice and to attempt to replicate results.

\section{Rural School Reform Efforts}

Addressing school reform from a rural perspective, as well as the challenges that rural school districts face, is an important component in improving our American public school system. Over $20 \%$ of all students in America are identified as being enrolled in a rural school, rural school district enrollment is growing at a faster pace than non-rural school districts, and factors of race, poverty, and special education needs increasingly add complex layers to rural education (Strange, Johnson, Showalter, \& Klein, 2012). Additionally, the federal government specifically addresses the need to provide specific funding and support for rural school districts in A Blueprint for Reform by providing technical support and improving traditional capacity constraints (U.S. DOE, 2010). As a result, a need exists to study how school reform efforts in rural settings are implemented, how they differ from nonrural settings, and why school reform efforts in rural settings may need to vary from non-rural settings.

Rural schools can have similar levels of poverty compared to their urban counterparts and often struggle to retain high performing educators in a similar manner as highly urbanized school districts (Ayers, 2011). Additionally, while many rural schools often serve as a center for community activity and pride, rural school systems can also struggle connecting and communicating with families (White \& Sheridan, 2011). As rural school districts help implement reform efforts within individual school buildings, it is important to engage the community with the reform effort to garner support and inform the community of changes in school practices. Just as important, school district personnel need to have a strong relationship with the building principal to provide the political support necessary to impart change in an often ingrained system of instruction.

Often rural school districts are charged with implementing reform efforts without an increase in budgetary support needed to enact improvement measures. Johnson (2006) posits that a lack of financial resources perpetuates achievement gaps for rural students, particularly among low socioeconomic students. As rural school districts attempt to implement school reform efforts to improve student achievement, practitioners and researchers need to acknowledge these efforts may look different than in non-rural settings, and that rural improvement efforts 
may require creativity to solve contextual problems of improvement (Nelson, 2010). Moreover, understanding how and why rural school districts determine creative solutions to support school reform implementation could lead to a greater understanding of federally funded reform policies and inform practitioners, researchers, and policy makers to provide insight to the creation of future school reform efforts.

\section{Method}

This research is a re-analysis of the Mette (2013) dataset which originally explored the application and transformation of a Midwest State Turnaround Schools Project. As previously noted, the current study aims to extend this original work by more closely examining proximal process factors underling rural school success. With federally provided funds, the State Department of Education (SDOE) created a program of support to help improve the lowest performing schools in the state. Using the University of Virginia (UVA) Turnaround Program as the foundation for professional development training, the SDOE developed a statewide turnaround model that provided ongoing support targeting the improvement of student achievement through improved executive leadership of school building principals. The UVA Turnaround Program was chosen by the SDOE due to the fact the model was a two-year program focusing on the best practices of business and education to support executive leadership. Thus, the goal of the State Turnaround School Project was to incorporate the key components of the UVA Turnaround Program and over time incorporate the training received to develop a sustainable, statewide SDOE model of turnaround support.

Four school districts participated in this study two from a rural region and two from an urban region. Participants from each district included the school building principal, as well as a district-level administrator. Within the rural region, the two participating districts were chosen due to their a) State Turnaround Schools Project successful implementation, b) two consecutive years of proficient state standardized scores, and c) willingness to take part in the study. Within the urban region, the two school districts were chosen due to their a) school reform improvement efforts prior to the State Turnaround School Project, b) participation in a previous evaluative study, and c) willingness to take part in the study.

With the support of multiple Local Centers for Professional Development (LCPD) that are funded by the SDOE to provide ongoing support for school improvement efforts, the goals of the State
Turnaround Schools Project were to help improve the instructional practice of leaders, the ability to evaluate programs and determine instruction via the use of data, and the effectiveness of teacher evaluations. In order to determine the role the LCPD played helping implement the reform effort, a LCPD leader was interviewed from each region, as well as two SDOE staff members who were in charge of supporting schools through School Improvement Grant (SIG) funding. Additionally, an ex-SDOE official, who developed and launched the State Turnaround Schools project, was also interviewed. As such, a purposeful selection of participants at the state level was developed based on support of turnaround school policy implementation.

Field notes, observational data, and interviews were collected to create a better understanding of how school reform efforts were influenced by theory and practice (Stake, 2010). Participant feedback and validation helped inform the study, providing participants the opportunity to review transcripts, clarify thoughts and comments, and ultimately provided participants with a voice to help determine the outcome of the study (Corbin \& Strauss, 2008). Using semi-structured interview questions, follow-up questions were determined by initial responses and the interview questions varied in an attempt to respond to individual conversations between the participant and the interviewer. Interviews occurred at the discretion of the participant(s), usually occurring during the school day. A voice recorder was used in all cases at the consent of the participants, and all interviews were transcribed verbatim for analysis. Axial coding was used to identify themes (Strauss \& Corbin, 1998), by organizing information into properties, dimensions, and subthemes, and connecting this information to broader themes that emerged throughout the study.

\section{Findings}

Previous findings from this dataset have detailed the importance of turnaround schools clearly communicating with turnaround consultants and support personnel, providing district support and promoting community involvement, and the necessity of employing a shared leadership and shared accountability approach (Mette, 2013). These findings detail what comprised successful turnaround in the two rural school buildings; however the current research addresses the details of how and why the two rural schools were successful in their turnaround policy implementation. Specifically, this article seeks to understand the processes used by the rural schools and detail the transformation of turnaround school policy theory into practice. 


\section{Process of Communication}

After leaders from the building and district levels received training from the State Turnaround Schools Project, with the ongoing support of the LCPD staff, they were charged with implementing what they learned and provided consultation updates with the UVA trainers and staff. If the school buildings needed anything to help their school turnaround efforts, they were first to work with their LCPD staff to address areas of improvement. If they needed additional support, they were to contact the UVA staff, who usually contracted out additional support to the school buildings (for example, presenter on data teams, administrative walkthroughs). The intended structure of communication was to directly aid individual schools, which were supported by district-level personnel, to work with the LCPD staff to implement the training provided by UVA staff.

The two rural schools that were successful in implementing the State Turnaround School Project worked closely with both LCPD staff as well as with UVA trainers. LCPD staff provided monthly meetings that allowed districts partaking in the State Turnaround Schools Project to network with other turnaround schools, share out important practices that showed student achievement improvement, and help address how to improve instructional practices within classrooms. The rural LCPD director reflected on how the schools implemented the turnaround reform efforts:

Our principals met monthly at our office for networking... We visited each school monthly, and those were walkthroughs. At times I did a lot of modeling in classrooms...the administrative support people, they did more mentoring with the principals. But it was typically we would go in their building, sit down for an hour, 'How are things going? Is there anything I can support you on?' That type of thing.

Through the close and continual support of LCPD, the rural schools became increasingly invested in the turnaround process. Via meetings with district leadership teams, LCPD and UVA turnaround staff helped to address 90-day improvement plans that were enacted to sustain improvement by meeting short-term target goals. If any piece of the 90-day plan was not met, or resources were not available to accomplish the plan, UVA provided additional support via presentations, webinars, or additional trainers. Comments from staff acknowledge appreciation of the support provided.

They gave us training on data teams, they gave us training on creating the culture, I mean we had lots of good presentations and good training while we were there, but it was never, when you go back, make sure that you do these nine things and this should be.... It was go back and start this, and we're here to support you....

In addition to support, UVA monitored progress and helped keep personnel on track with goals. One principal commented:

They [UVA] meet with us as principals and checked in on us. We had the 90-day plans and actions that we were going to do, and they had all the different pieces that we needed and then you have to, you know, how are you going to sustain this? And what are you going to use to measure this? They kept a very close eye on us to make sure that we were keeping in line with what our goals were and making sure that we had all the pieces. And if we didn't they would let you know. We had to send them information and then they would call us or do a webinar with us, or they would actually come and talk to us.

The LCPD director from the urban region, however, stated upfront communication about what the State Turnaround Schools Project offered was absent. He stated that there lacked a "syllabus" or a clear plan of communication that he believes is critical for preparing school leaders for turnaround efforts. What he experienced was the State Turnaround School Project releasing pieces of information as the program unfolded, rather than stating the goals of the program upfront. The urban LCPD director also mentioned the lack to communication from the SDOE regarding the "deliverables" of the State Turnaround School Project, specifically what the district would be required to provide, and what actions the school leaders would have to display. Additionally the urban participants stated a concern about the lack of use of peer-reviewed educational literature in the training. Some participants stated that while lessons can be learned from the business world, school boards or principals do not always have as much autonomy as businesses do. One urban district administrator stated:

I don't think they felt obligated to prove to us that they knew what they were talking about. I think they acted more like they assumed that we would assume that they knew what they were talking about. And that if they were recommending practices to us, that they were research-based practices.

A principal from a different urban district also commented that there is not a great deal of research on turnaround schools and that it is still a highly theoretical area of inquiry.

Our work with UVA was very theoretical. "Good to great." Great! "Good to great." Put that in the context of um... helping me move mediocre 
teachers to greatness. That's what was missing from the program.

This principal went on to talk about how the concept of turnaround itself lacks a common definition, and she questioned how schools can measure the concept of sustainability without having long-term data. The urban LCPD director felt that evidence for the efficacy of the State Turnaround School Project was limited to referencing previous participants and highlighting how other leaders had implemented the program within their school buildings. He also stated he could not remember any hard data provided from any one school referencing student achievement growth using benchmark assessments and that he did not recall seeing a large amount of school-related data to support the field of turnaround.

One reason the two rural school districts appeared to be successful in the turnaround school implementation is due to the fact that they accepted the training of the outside consultant as opposed to rejecting participation. The rural LCPD director reflected on why the participating schools accepted the training provided in the State Turnaround Schools Project, and commented on the isolation of the area, the lack of local funding to support large reform efforts at the district level, and the reliance on the LCPD to help provide ongoing professional development. "They [the rural school districts] really rely on us to help improve their schools.... We're a community, and it's very familial around here." By accepting technical support from an outside consultant with the support of the trusted rural LCPD, as well as financial assistance to improve the quality of the professional development provided, the two rural school districts were able to meet school improvement needs.

\section{Providing District Support and Promoting Community Involvement}

In the two rural districts that experienced successful turnaround, both principals commented they were able to make more decisions from a sitebased perspective because the district is smaller and the needs are specific to their schools. The principals also mentioned knowing they have the support of their school board and their central office to make whatever changes are necessary was an integral part of their success. Both principals observed many of the schools from other districts attending the UVA training did not seem to have this autonomy. One rural principal reflected on a conversation where her superintended provided additional funding necessary for an assessment program:
We had a whole list of things that we wanted to do and of course that takes money, and so we set up a meeting with the superintendent and the three of us went over and we just told him what the important aspects, what we just felt like we were going to have to do. And one of them was getting, which, and that was, getting a ... a STI... a benchmark assessment program. We needed somebody to come in and build this for us.

Because there was no way, we didn't have the resources.

Another rural principal reflected on how she observed other turnaround school principals struggle to receive support from central office administrators: I had principals [in my training] that it was a fight for them to change anything. Their school board and their [superintendent] - they didn't have the support that I did.... They, and I mean, I'm not going to lie, I know there were several principals that they ended up leaving their jobs because, it's like they weren't going to let them change. You know what I mean?

While the two successful rural participants do produce some evidence that turnaround school policy can be successful, a key element is identifying how the school building and central office leaders chose to implement the turnaround school policy. The districts that supported individual schools that successfully implemented turnaround chose to work closely with the State Turnaround Schools Project trainers, openly communicate the turnaround process with all stakeholders, place strong leadership their turnaround buildings, and provide a high level of district support.

Another important area of rural school turnaround is the notion of promoting community involvement by addressing the local concerns of students, parents, and community members. One rural principal commented.

Like I said, the ...bully-free/fight-free program that we just implemented, and we actually went to the community and, we're calling it [our Mascot] Crusade, and it's our fight against bullying.... We're not going to tolerate it anymore. I want every child to come here and feel safe and want to come to school and not cry because they don't want to come because people are bullying them. And [students are] telling their parents or their grandparents that they don't want to live anymore and they're nine years old? So we have had this big push and we've seen an improvement in it... and the community joined in to help us.

Moreover, the successful rural principals reflected on the specific work that was required to listen to the stakeholders to create greater buy-in within the community, specifically reflecting on the training 
they received during their time participating in the State Turnaround Schools Project.

Dealing with people. A lot of it was how you take your clientele and work with them and convince them to do what you want them to do. The best I remember was, 'How are you going to get people to follow you as a leader?' It was from a business point of view rather than as a principal. Getting the buy-in from whoever it is, the community or the parents or the kids or your teachers or whoever it is.

As a result, there exists a real need to understand how rural leaders can engage the community and understand why this is such an important aspect of creating school turnaround in a rural area.

In addition to working with the community to address local concerns, the rural school participants mentioned the reality of negotiating the politics that can be pervasive in more rural areas.

But that's part of small town, what's it called? Small town politics. Good old boy politics. Good old boy system. I don't know, but one thing about the town... and the school board, and the district, they knew, they knew we had to make a change.

After that tornado hit here five years ago...it took its toll on the economy, and took its toll on the whole community.

The two successful schools districts clearly understood the need for support of the turnaround process at the district level, allowing for them to openly convey a change in practice that signals to the teachers, students, and stakeholders of the school district that school turnaround efforts are top district priority. Consequently, these schools were able to address change in the context of the needs of the community and work in a collaborative manner to address how the school, the school district, and the community could work together to promote improved student achievement and a high standard of living.

\section{Shared Leadership and Shared Accountability}

Perhaps the most important aspect of the State Turnaround Schools Project training for a majority of the schools that participated was the improved ability for leaders to target areas of needed improvement among staff and empower other leaders within the building to further develop the school with shared leadership. The school building principals that were successful implementing school turnaround efforts were invested in the process, knew exactly what they needed to improve upon, sought the leadership of teachers within the building, and actively sought out the assistance of the LCPD staff to provide the professional development necessary to help teachers make strides towards improvement.
[I have] an instructional coach and now she is in charge of our testing, and every single week she has questions for them, or she has charts for them to do. All it's doing is tracking their teaching to see where they are weak and where they are strong. We're also at a point in this building after probably the first year, that we can discuss those bad scores and people not be crying when we leave.

The rural LCPD director felt that these schools that were successful in the program were not solely successful because of the State Turnaround School Project training, but also because of the style of leadership that existed in the building.

You've got to have really great leadership for that to be effective at the school level.... The schools who were effective had excellent leadership.... They were instructional leaders. They didn't just manage the building. They were involved in every piece of it along the way. They were in the trenches with them.

Both rural principals acknowledged the State Turnaround Schools Project made their staffs more accountable to understanding where their students are academically and what instruction they need to provide to help them become proficient, which supports the idea of working collaboratively to meet the diverse needs of students.

Well, like I said, and I think we talked about this a little earlier, as far as how it impacted the staff, they had to become more accountable for everything that they did within their classroom. They have a more in-depth understanding of where there kids are and where they need to take them. Collaboration. They realize how important collaboration is... among themselves and grade levels.

One rural district administrator stated she felt that the State Turnaround Schools Project was helpful in creating turnaround, but that success was also dependent on the willingness of the principal to make immediate changes through action, and that this commitment trickled down to staff members in the building. The district administrator went on to say that the principal of this rural turnaround school was very direct, honest, and realistic about addressing the low student achievement of the school building. Moreover, she is "in the trenches" with the teachers and leads by example, which greatly impacts the culture of the building. Both successful turnaround principals commented that in order to work at their school, teachers need to be "willing to do whatever needs to be done" and "do whatever it takes to work with these kids" to help students make improvements. As a result, both of these principals were able to turn their schools around as a result of 
not only leadership, but a type of leadership that is hands-on and can create change by modeling action.

The rural LCPD director felt the schools who received professional learning community (PLC) training prior to partaking in the State Turnaround Schools Project were able to make quick student achievement improvement because of their experience leading collaborative leadership teams. Rather than a top-down approach to leadership, school improvement team members collaborated to hold each other accountable. The LCPD director observed:

Here's something else that a lot of people may or may not identify, but our two schools... who were successful in the program, both of them had been professional learning communities prior to going into the turnaround project.... They were a continuing school in the PLC project, so they had had tons of that collaborative team time. Just building the collaborative culture. Most of our schools had not, had never thought of having collaboration time with other teachers.

The two schools that did make improvement from this region had implemented the PLC process prior to implementing turnaround reform efforts. Moreover, because they had also received a lot of professional development in purposeful collaborative team time and building a collaborative culture, they were perhaps more ready to take on the State Turnaround Schools Project training. As a result, shared leadership and accountability did influence implementation in the sense that in order for turnaround efforts to be successful, staff members had to learn to work together to think differently about collaboration to create lessons that support academically successful students, how data must be used to influence adult behavior to better address the needs of students, and how staff members must be accountable to each other to work as a PLC.

\section{Discussion}

This research aims to address how rural schools can serve their community in creative ways while simultaneously responding to the pressures of school improvement efforts and extends past findings on school turnaround (Mette, 2013) by detailing how and why rural schools were able to successfully implement turnaround school policy. Findings highlight the importance of a partnership based on clear communication, support and accountability between turnaround consultants and school officials, the presence of strong district support for school building administration for turnaround school policy implementation, and the positive impact shared leadership and shared accountability has on transforming the culture of a turnaround school.

In order to better meet the needs of the teachers and principals as adult learners, the rural LCPD director felt if the participating turnaround schools were to make a difference in the communities they served, the building principals and school district administrators had to work closely with the UVA Turnaround staff to ensure ongoing support as the reform effort was implemented, strengthen the relationship between the school building principal and central office to ensure the turnaround school could focus entirely on implementing the reform effort, and work closely with the support of the LCPD to model specific professional development on how to use data to improve instructional staff member performance. An example provided was how one LCPD assessed baseline knowledge of the participating teachers' skillsets in order to provide targeted support and professional development of educators. An outcome of this process is what the LCPD director refers to as a "roadmap of professional development" that allows principals to target who they must work with and what they must work on in order to improve the quality of the instructional staff. As such, the use of data not only informs instructional decisions, but also determines adjustments adults have to make in order for students to be successful.

The regional differences regarding the perceived value of the State Turnaround School Project participation provides valuable insight as to perhaps why the rural region was more successful than the urban. The rural LCPD director felt the State Turnaround School Project training was excellent; however, the support she provided to her schools was much more specific than what she learned from the State Turnaround School Project. While she felt the training was good, it was not aligned to the specific needs of the districts involved in the program, and she took it upon herself to transform the support being provided to meet individual needs. As a result, how improvement was provided by the rural LCPD is a result of specific training on improved teacher instruction by modeling more engaging instructional practices for teachers, conducting more focused evaluation of teachers to target needed professional development, having difficult conversations with under-performing teachers, and managing time and resources more efficiently in a building. By listening to the specific needs of the participating turnaround schools, the rural LCPD was able to provide much needed practical implementation support that could be used immediately in a building to help bring about improvement. 
Because she attended the training, the rural LCPD director felt she better understood the goal of the program and was able to act as bridge between administrators and teachers who did not attend the training. The rural LCPD who helped support the two successful turnaround participants seemed to serve as the "glue" between the administrators and teacher leadership teams and the training personnel of the State Turnaround School Project. This seems to address why the rural region was perhaps more successful in implementing the turnaround reform effort. Additionally, the rural LCPD staff member felt that she was aware of the potential for an implementation dip during the second year of implementation she was better prepared to support the continual improvement of student achievement in the participating schools. As a result, the rural LCPD group came into the regional school buildings to see how they could help rather than inviting educators to come to them. The monthly meetings provided time to reflect on implementation of 90-day plans and identify what strategies were working and what needed to be changed or adapted. Through these monthly meetings, a network was created for the turnaround schools in this rural region where they could share successes with each other. However the rural LCPD provided more than just networking opportunities - it helped identify workshops and offered professional development, including, but not limited to: training on administrative walkthroughs using the Instructional Practices Inventory (IPI), Response to Intervention (RTI), Writer's Academy, new teacher training, high-quality engagement instruction activities, and modeling data team meetings to help focus on instructional improvement. Specifically, one principal mentioned the professional development that the rural LCPD provided in order to help teachers improve instruction so that students' individual needs can be met (e.g., modeling lessons). This additional layer of schoolfocused support most likely helped play a crucial part in why there was more successful turnaround in one region and not the other.

\section{Conclusions and Implications}

The participating rural region is, by nature, smaller and more community-based. All but one participant in the State Turnaround School Project study mentioned the fact that they believed school turnaround was easier to accomplish in a smaller, more community-based district, because of the ability to serve the needs of the students in a turnaround school building as opposed to the political needs of a larger district itself. In the two rural districts, the size of the district was smaller than their urban counterparts and the turnaround communication plans were clearer and more concise with regard to students, teachers, and community members, allowing the rural districts to better support the needs of the turnaround school. Additionally, in the rural districts, principals were better able to assess the instructional needs of teachers to promote a culture of shared leadership and accountability.

Moreover, the participants from the rural region seemed more willing to change the behaviors of the adults to increase the success of their students, even although this meant much more work for the teachers. While the participating principals of the rural region acknowledged that the additional work put a stress on their faculty members, they also stated the culture of their building had completely changed, to the point that the shared accountability of the building now drives the work of all employees because the focus of the educators is to build on the success of the increased student achievement. The ability of school leaders to implement school turnaround reform efforts reflects the expectations of the different regions, including the leadership role the LCPD provided in the rural region to help identify necessary professional development that impacted the success of the State Turnaround School Project.

Additionally, there is a real need to acknowledge that in order to turn a school around, the relationship between the turnaround consultant, the school, and school district must be clearly articulated. Both sides must understand the required shift in perspectives, actions, and expectations, not only of themselves but of each other. Once a clear line of communication has been established regarding the turnaround process, it appears that schools will be more likely to find success in completing a school turnaround program. The second aspect that must accompany clear communication is the notion that drastic school improvement must be supported at the district level. Without the support of the school district to openly promote school turnaround efforts within the community, as well as the existence of a strong relationship between central office personnel and the principal of the turnaround school, school turnaround will most likely not occur. Therefore, there is a great need to drive school improvement from the district level with clear communication and support from the turnaround consulting agency. In doing so, the school and school district are able to engage the community in the turnaround process and transform the school reform effort into a community-based improvement plan.

The third facet of school turnaround, and perhaps the most important vehicle to drive change, is the concept that building-level leadership matters. The schools that successfully implemented the State 
Turnaround School Project training into their everyday practice seemed to go beyond the training provided. These schools had highly interpersonal leaders who were able to build relationships, not only with the teachers and students in their school buildings, but also with the LCPD staff members as well as the UVA Turnaround trainers. In doing so, these highly skilled interpersonal leaders were able to influence the fourth aspect that is required in school turnaround, changing the school culture to promote shared leadership and shared accountability within their school buildings. With the support of teacher- leaders, the turnaround principals worked together to develop a mission and vision for their school buildings that allowed their respective faculty members to take part in a shared-decision making process and increase buy-in to the school turnaround program. By identifying individual strengths among their faculty members, and finding ways to provide professional development to address individual weaknesses, these leaders were able to implement school improvement in the face of daunting accountability standards, improve their school climate, and ultimately improve student achievement.

\section{References}

Ayers, J. (2011). Make rural schools a priority: Considerations for reauthorizing the Elementary and Secondary Education Act. Washington, DC: Center for American Progress.

Bibeault, D.B. (1982). Corporate turnaround: How managers turn losers into winners. New York: McGraw-Hill.

Boyne, G.A. (2006). Strategies for public service turnaround: Lessons from the private sector? Administration \& Society, 38(3), 365-388.

Corbin, J., \& Strauss, A. (2008). Basics of qualitative research ( $3^{\text {rd }}$ ed.) Los Angeles: Sage.

Duke, D.L. (2008). Keys to sustaining successful school turnarounds. Charlottesville, VA: Public Impact.

Erwin, S., Winn, P., \& Erwin, J. (2011). A comparison of urban, suburban, and rural principal leadership skills by campus student achievement level. Administrative Issues Journal: Education, Practice, and Research, 1(2), 3-17.

Harrigan, K.R. (1988). Strategies for declining industries. In K. S. Cameron, R. I. Sutton, and D. A. Whetten (Eds.), Readings in organizational decline: Frameworks, research, and prescriptions (pp. 129-149). Cambridge, MA: Ballinger.

Johnson, J. (2006). Compounding challenges: Student achievement and the distribution of human and fiscal resources in Oregon's rural school districts. Washington, DC: Rural School and Community Trust.

Leithwood, K., \& Strauss, T. (2008). Turnaround schools and the leadership they require. Toronto, ON: Canadian Education Association.

Mette, I.M. (2013). Turnaround as reform: Opportunity for change or neoliberal posturing? Interchange, 43(4), 317-342.

Murphy, J. (2008). Turning around failing schools: Policy insights from the corporate, government, and nonprofit sectors. Educational Policy, 23(6), 796-830.

Murphy, J. (2010). Turning around failing organizations: Insights for educational leaders. Journal of Educational Change, 11(2), 157-176.

Murphy, J., \& Meyers, C. V. (2008). Turning around failing schools: Leadership lessons from the organizational sciences. Thousand Oaks, CA: Corwin.

Monk, D. (2007). Recruiting and retaining highquality teachers in rural area. The Future of Children, 17, 155-174.

Nelson, S. (2010). Leveraging the unique features of small, rural schools for improvement. Lessons Learned, 1(5), 1-4.

O'Neill, H.M. (1986). An analysis of the turnaround strategy in commercial banking. Journal of Management Studies, 23(2), 165-188.

Pearce, J. A., \& Robbins, D. K. (1993). Toward improved theory and research on business turnaround. Journal of Management, 19(3), 613636.

Schuchman, M.L., \& White, J.S. (1995). The art of the turnaround: How to rescue your troubled business from creditors, predators, and competitors. New York: American Management Association.

Slatter, S., Lovett, D., \& Barlow, L. (2006). Leading corporate turnaround: How leaders fix troubled companies. San Francisco: Jossey-Bass.

Stake, R.E. (2010). Qualitative research: Studying how things work. New York: The Guilford Press.

Strange, M., Johnson, J., Showalter, D., \& Klein, R. (2012). Why rural matters 2011-2012: The condition of rural education in the 50 states. Washington, DC: Rural School and Community Trust.

Strauss, A.L. \& Corbin, J. M. (1998). Basics of qualitative research: Techniques and procedures 
for developing grounded theory. Thousand Oaks, CA: Sage.

Trujillo, T. \& Renée, M. (2012). Democratic school turnarounds: Pursuing equity and learning from evidence. Boulder, CO: National Education Policy Center.

US Department of Education, Office of Planning, Evaluation and Policy Development. (US DOE)
(2010). ESEA Blueprint for Reform. Washington, D.C.

US Department of Education. (US DOE) (2011). Turnaround schools. Retrieved from http://www.ed.gov/blog/2010/04/support-forturning-around-low-performing-schools/

White, A. L., \& Sheridan, S. M. (2011). Family engagement in rural schools. Retrieved from http://r2ed.unl.edu/

\section{About the Author}

Dr. Ian Mette is an Assistant Professor of Educational Leadership in the College of Education at the University of Wyoming. His research interests include school reform, accountability policies, and instructional supervision. Correspondence regarding this article can be directed to ianmette@gmail.com. 